\title{
Permodelan Hidrologi Daerah Aliran Sungai Sengkarang Kabupaten Pekalongan Dengan Perangkat Lunak HEC-HMS
}

\author{
Angsa Dilaguna $\mathrm{B}^{1}$,Tamara Budi $\mathrm{A}^{1}$, Budi Santosa ${ }^{2}$ \\ Email: angsadila09@gmail.com, tamaralala@ymail.com
${ }^{1}$ Program Studi Teknik Sipil, Fakultas Teknik, Universitas Katolik Soegijapranata, Jl. Pawiyatan Luhur IV/1, Bendan Dhuwur, Semarang 50234
${ }^{2}$ Dosen Program Studi Teknik Sipil, Fakultas Teknik, Universitas Katolik Soegijapranata, Jl. Pawiyatan Luhur IV/1, Bendan Dhuwur, Semarang 50234

\begin{abstract}
Along with the increase of human population, the necessity of housing will increase as well. Therefore land use change cannot be avoided. Land use change on watersheds (DAS) is one of the causes of flood. The purpose of this study is to examine the changes of hydrograph on watersheds caused by land use change within 20 years. The data used in the form of rainfall data in 2011-2016, land use maps in 2011 and 2031 and topographic maps of soil types. Using HECHMS software will be obtained the results of 2011 and 2031 river flow hydrograph. The results of this modeling were compared to find out the Peak Discharge at weir Ps. Kletak. In 2-year return period of 2011 and 2031 are $662,6 \mathrm{~m}^{3} / \mathrm{s}$ and $770,8 \mathrm{~m}^{3} / \mathrm{s}$ with increase $16.33 \%$, and for a 50-year return period of 2011 and 2031 are sebesar $1643,2 \mathrm{~m}^{3} / \mathrm{s}$ dan $1774,2 \mathrm{~m}^{3} / \mathrm{s}$ with increase $7.97 \%$.
\end{abstract}

Keywords: Watershed (DAS), HEC-HMS, Land Use

\section{PENDAHULUAN}

\subsection{Latar Belakang}

Air dihasilkan dari penguapan air laut menjadi awan, awan tersebut membawa air yang akan dijatuhkan kembali ke permukaan bumi dalam bentuk hujan. Air memiliki peran penting untuk kehidupan makhluk hidup sebagai kebutuhan pokok kehidupan sehari-hari.

Di propinsi Jawa Tengah tepatnya di Kabupaten Pekalongan yang secara geografis terletak antara $6^{\circ}-7^{\circ} 23^{\prime}$ LS dan $109^{\circ}-109^{\circ} 78^{\prime}$ BT. Memiliki luas daerah sebesar $836,13 \mathrm{~km}^{2}$. Sungai besar yang mengalir di Kabupaten Pekalongan yaitu Sungai Sragi dan Sungai Sengkarang.

Sungai Sengkarang mengalir dari hulu yang terletak pada pegunungan Serayu Utara tepatnya di Gunung
Rogojembangan serta Pegunungan Kendalisodo di Desa Gumelem, Kecamatan Petungkriono. Sungai Sengkarang memiliki panjang sekitar 52 $\mathrm{km}$ dan bermuara ke Laut Jawa. Luas daerah aliran Sungai Sengkarang kurang lebih 308,23 $\mathrm{km}^{2}$. Pemanfaatan dari sungai ini adalah untuk pengairan/ irigasi melalui beberapa bendung.

Potensi banjir di sungai Sengkarang membesar ketika memasuki musim hujan. Hal ini dikarenakan perubahan tata guna lahan yang setiap tahunnya terus meningkat. Maka penting untuk dilakukan penelitian guna mengetahui pemodelan hidrologi untuk daerah aliran sungai Sengkarang.

\subsection{Rumusan Masalah}

Tanggul sungai dan tanggul penahan gelombang di muara Desa Jeruksari, Kabupaten Pekalongan, Jawa 
Tengah jebol dan aliran air sungai ini langsung masuk ke lahan tambak, sawah dan permukiman penduduk. Tanggul ini jebol dikarenakan hujan deras.

\subsection{Tujuan Penelitian}

Tujuan dari penelitian ini adalah:

a. Mengetahui karakteristik DAS Sungai Sengkarang ditinjau dari bentuk DAS dan tata guna lahan.

b. Mengkaji perubahan hidrograf aliran Sungai Sengkarang akibat perubahan tata guna lahan untuk periode 20 tahun $(2011$ - 2031) menggunakan Software HEC-HMS.

\section{TINJAUAN PUSTAKA}

\subsection{Daerah Aliran Sungai}

Daerah Aliran Sungai atau DAS merupakan suatu wilayah atau daerah dari suatu sungai yang terpisah karena adanya bukit atau gunung. DAS menerima air hujan dan sedimen yang kemudian terkumpul dan dialirkan menuju sungai utama dan anak - anak sungai.

\subsection{Daur Hidrologi}

Daur hidrologi dimulai dengan penguapan air kemudian uap air ini akan membeku menjadi awan. Uap - uap air yang telah membeku menjadi awan kemudian menyatu menjadi gumpalan awan yang memiliki butiran - butiran air di dalamnya. Kemudian awan akan menjatuhkan butiran - butiran air tersebut ke permukaan bumi.

\subsection{Hujan}

Hujan merupakan jatuhnya butir - butir air yang terkandung pada awan dari atmosfir ke permukaan bumi. Hujan dapat diukur dengan alat penakar hujan. Hujan yang dapat diukur adalah hujan yang jatuh ke permukaan tanah.

\subsubsection{Analisis Curah Hujan}

Dengan menggunakan metode thiessen merupakan metode perhitungan dengan cara melakukan rata-rata timbang (weighted average). Pada metode ini masing - masing penakar hujan mempunyai daerah pengaruh masing - masing yang dibentuk dengan menggambarkan garis - garis sumbu tegak lurus terhadap garis penghubung antara dua pos penakar.

\subsubsection{Analisis Frekuensi}

Analisis frekuensi merupakan analisis secara statistik curah hujan rata- rata dari berbagai stasiun yang ada pada daerah aliran sungai. Analisis frekuensi bertujuan untuk mendapatkan pola sebaran data curah hujan yang sesuai dengan pola sebaran data curah hujan rata - rata.

\subsubsection{Pemilihan Jenis Sebaran}

Berikut merupakan macam macam distribusi yang digunakan untuk mengalisis probabilitas banjir:

a. Distribusi Normal

$P(X)=\frac{1}{\sigma \sqrt{2 \pi}} \cdot e^{-\frac{1}{2}\left[\frac{X-\mu}{\sigma}\right]^{2}}$

b. Distribusi Log Normal

$X_{t}=\bar{X}+K_{t} \cdot S$

c. Distribusi Gumbel Tipe 1

$X_{T}=\bar{X}+\frac{S}{S_{n}} \cdot\left(Y_{T}-Y_{n}\right)$

d. Distribusi Log Pearson Tipe III

$C s=\frac{\sum_{i=1}^{n}\left\{\log \left(X_{i}\right)-\log (\bar{X})\right\}^{3}}{(n-1)(n-2) s^{3}} \quad \ldots \quad(4)$

\subsubsection{Pengujian Distribusi \\ Kecocokan}

Pengujian kecocokan sebaran digunakan untuk menguji apakah sebaran tersebut dapat memenuhi syarat untuk data perencanaan. Pengujian kecocokan dapat dilakukan 2 cara.

a. Perhitungan Chi Kuadrat

b. Perhitungan Smirnov Kolmogorov

\subsection{Tata Guna Lahan}

Menurut Peraturan Pemerintah nomor 16 tahun 2004, tata guna lahan adalah pengelolaan lahan baik dalam hal penggunaan, penguasaan dan 
pemanfaatan tanah untuk kepentingan masyarakat secara adil melalui pengaturan kelembagaan terkait. Dengan begitu tata guna lahan merupakan pemanfaatan tanah dengan perubahan bentuk yang awalnya berupa lahan persawahan berubah menjadi lahan pemukiman.

\subsection{Banjir}

Banjir merupakan bencana alam yang sering terjadi, terutama saat musim hujan. Menurut Rahayu (2009), banjir merupakan tergenangnya suatu wilayah akibat dari meluapnya air yang melebihi kapasitas penampungan pembuangan air di suatu wilayah tertentu sehingga menimbulkan kerugian fisik, sosial dan ekonomi.

\subsection{Hidrograf Debit}

Hidrograf debit merupakan suatu grafik yang menggambarkan hubungan antara debit air dengan waktu.

\subsection{Model Hidrologi}

Model hidrologi adalah gambaran sederhana dari suatu sistem hidrologi yang aktual. Model hidrologi pada umumnya digunakan untuk mempelajari fungsi dan respon suatu DAS.

\subsection{HEC-HMS}

Menurut Davis (2000), HEC HMS adalah salah satu model hidrologi kategori model matematik. Model matematik tersebut berupa software program computer yang memiliki beberapa metode yang dapat mensimulasikan DAS, saluran dan perilaku bangunan air. Software HEC HMS dikembangkan oleh Hydraulic Engineering Centre (HEC) dari US Army Corp Of Engineers yang bertujuan untuk memberi prediksi output dari suatu sistem hidrologi.

\section{METODE PENELITIAN}

\subsection{Tahapan Penelitian}

Berikut merupakan diagram alir secara singkat namun mencakup secara menyeluruh sehingga mudah dipahami.

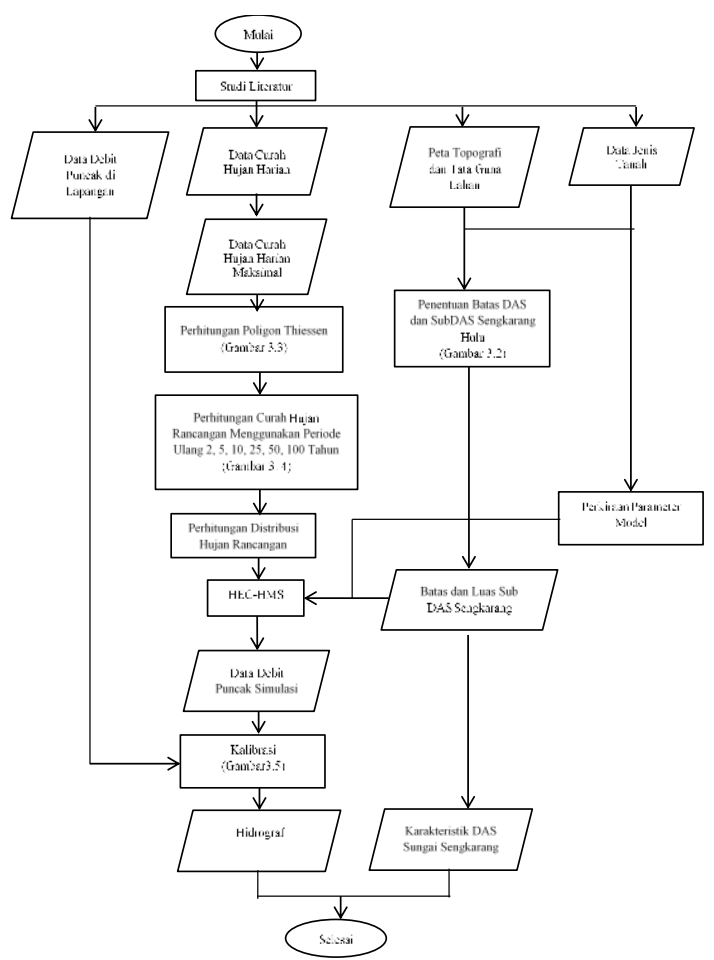

Gambar 3.1 Diagram Alir Secara Umum

\subsection{Pengolahan Data}

Berikut merupakan tahapan perhitungan yang dilakukan pada penelitian ini:

a. Penentuan Batas DAS dan SubDAS

Sengkarang

b. Perhitungan Poligon Thiessen

c. Perhitungan Curah Hujan Rancangan

d. Permodelan HEC-HMS

e. Perhitungan kalibrasi

\subsection{Parameter Penelitian}

Untuk mendapatkan hasil hidrograf digunakan perangkat lunak HEC-HMS. Berikut adalah tabel nilai untuk kalibrasi model HEC-HMS. 
Tabel 3.1 Nilai Parameter Untuk Kalibrasi Model HEC-HMS

\begin{tabular}{|l|l|l|l|}
\hline Model & Parameter & Min & Max \\
\hline \multirow{2}{*}{ SCS Loss } & Initial abstraction & $0 \mathrm{~mm}$ & $500 \mathrm{~mm}$ \\
& Curve number & $0 \mathrm{~mm} / \mathrm{hr}$ & 100 \\
\hline SCS UH & Lag & $0.1 \mathrm{~min}$ & $30000 \mathrm{~min}$ \\
\hline
\end{tabular}

Sumber: Suhartanto, 2008

\section{PEMBAHASAN}

\subsection{Analisa Penggunaan Lahan}

Peta penggunaan lahan yang digunakan yaitu peta tata guna lahan Kabupaten Pekalongan tahun 2011 dan tahun 2031. Dengan menggabungkan peta tata guna lahan dan SubDAS Sengkarang pada ArcMap dengan perintah union akan didapatkan besaran penggunaan lahan pada tiap SubDAS. Gambar 4.1 menunjukan penggunaan lahan pada tahun 2011 dan Gambar 4.2 menunjukan penggunaan lahan 2031.

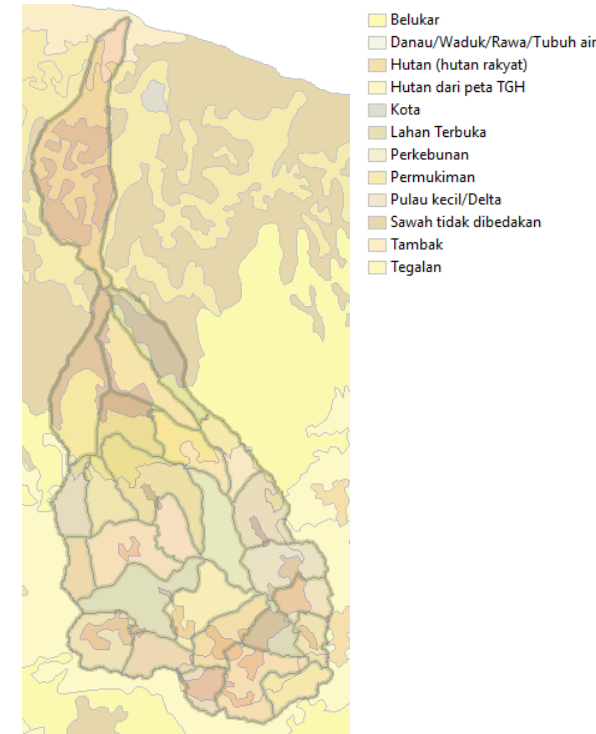

Gambar 4.1. Penggunaan lahan tahun 2011

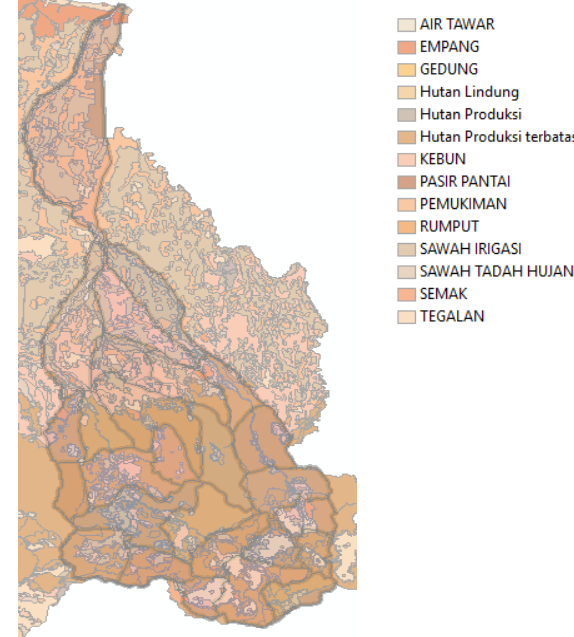

Gambar 4.2 Penggunaan Lahan tahun 2031

Berikut adalah Tabel 4.1 yang menunjukkan hasil penggunaan lahan pada tahun 2011 dan 2031 pada DAS Sengkarang dan perubahan yang terjadi dalam 20 tahun.

Tabel 4.1 Penggunaan lahan DAS

Sengkarang tahun 2011 dan 2031

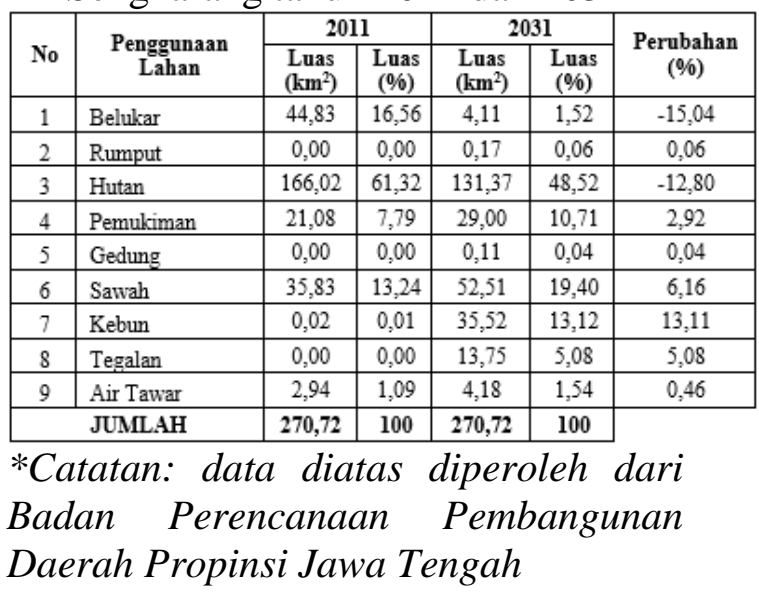

\subsection{Simulasi Model Hujan-Aliran DAS Sengkarang tahun 2011}

Nilai yang digunakan untuk input parameter Loss Model (SCS Curve Number) DAS Sengkarang 2011 adalah nilai yang sudah terkalibrasi. Tabel 4.2 berikut ini merupakan $\mathrm{CN}$, impervious dan initial abstraction DAS Sengkarang pada tahun 2011 untuk parameter Loss Model (SCS Curve Number). 
Tabel 4.2 Nilai CN, Impervious dan Initial Abstraction DAS Sengkarang Tahun 2011

\begin{tabular}{|c|c|c|c|}
\hline Sub DAS & CN & Impervious & Inirial Abstraction \\
\hline Sub DAS 0 & 75,01 & 25,85 & 16,93 \\
\hline Sub DAS 1 & 75,02 & 20,99 & 16,92 \\
\hline Sub DAS 2 & 71,01 & 5,02 & 20,74 \\
\hline Sub DAS 3 & 71,00 & 5,00 & 20,75 \\
\hline Sub DAS 4 & 71,00 & 5,00 & 20,75 \\
\hline Sub DAS 5 & 71,00 & 5,00 & 20,75 \\
\hline Sub DAS 6 & 71,00 & 5,00 & 20,75 \\
\hline Sub DAS 7 & 71,00 & 5,00 & 20,75 \\
\hline Sub DAS 8 & 71,00 & 5,07 & 20,75 \\
\hline Sub DAS 9 & 71,00 & 5,00 & 20,75 \\
\hline Sub DAS 10 & 71,00 & 5,00 & 20,75 \\
\hline Sub DAS 11 & 71,00 & 5,01 & 20,75 \\
\hline Sub DAS 12 & 71,00 & 5,01 & 20,75 \\
\hline Sub DAS 13 & 71,00 & 5,00 & 20,75 \\
\hline Sub DAS 14 & 71,00 & 5,00 & 20,75 \\
\hline Sub DAS 15 & 71,26 & 5,44 & 20,49 \\
\hline Sub DAS 16 & 71,00 & 5,22 & 20,75 \\
\hline Sub DAS 17 & 71,00 & 5,00 & 20,75 \\
\hline Sub DAS 18 & 71,62 & 6,69 & 20,13 \\
\hline Sub DAS 19 & 71,78 & 6,31 & 19,97 \\
\hline Sub DAS 20 & 71,94 & 6,56 & 19,82 \\
\hline Sub DAS 21 & 72,94 & 10,00 & 18,85 \\
\hline Sub DAS 22 & 74,28 & 15,27 & 17,59 \\
\hline Sub DAS 23 & 74,88 & 11,56 & 17,04 \\
\hline Sub DAS 24 & 75,88 & 15,00 & 16,15 \\
\hline Sub DAS 25 & 74,03 & 10,04 & 17,82 \\
\hline Sub DAS 26 & 74,96 & 15,00 & 16,97 \\
\hline
\end{tabular}

Nilai yang digunakan untuk input parameter Transfrom Model (SCS Unit Hydrograph Method) DAS Sengkarang 2011 adalah nilai yang sudah terkalibrasi. Tabel 4.3 berikut ini merupakan Lag Time DAS Sengkarang pada tahun 2011 untuk parameter Transfrom Model (SCS Unit Hydrograph Method).
Tabel 4.3 Nilai Lag Time untuk Parameter Transform Model (SCS Unit Hydrograph Method) DAS Sengkarang Tahun 2011

\begin{tabular}{|c|c|}
\hline Sub DAS & Lag Tume (menit) \\
\hline Sub DAS 0 & 53,11 \\
\hline Sub DAS 1 & 16,34 \\
\hline Sub DAS 2 & 2,33 \\
\hline Sub DAS 3 & 1,67 \\
\hline Sub DAS 4 & 1,51 \\
\hline Sub DAS 5 & 1,50 \\
\hline Sub DAS 6 & 1,54 \\
\hline Sub DAS 7 & 1,42 \\
\hline Sub DAS 8 & 1,47 \\
\hline Sub DAS 9 & 1,58 \\
\hline Sub DAS 10 & 1,77 \\
\hline Sub DAS 11 & 1,55 \\
\hline Sub DAS 12 & 3,09 \\
\hline Sub DAS 13 & 2,84 \\
\hline Sub DAS 14 & 1,63 \\
\hline Sub DAS 15 & 1,83 \\
\hline Sub DAS 16 & 1,67 \\
\hline Sub DAS 17 & 2,44 \\
\hline Sub DAS 18 & 2,74 \\
\hline Sub DAS 19 & 3,13 \\
\hline Sub DAS 20 & 2,58 \\
\hline Sub DAS 21 & 4,71 \\
\hline Sub DAS 22 & 9,90 \\
\hline Sub DAS 23 & 2,36 \\
\hline Sub DAS 24 & 5,92 \\
\hline Sub DAS 25 & 2,74 \\
\hline Sub DAS 26 & 3,52 \\
\hline
\end{tabular}

\subsection{Simulasi Model Hujan-Aliran DAS Sengkarang tahun 2031}

Nilai yang digunakan untuk input parameter Loss Model (SCS Curve Number) DAS Sengkarang 2011 adalah nilai yang sudah terkalibrasi. Tabel 4.4 berikut ini merupakan $\mathrm{CN}$, impervious dan initial abstraction DAS Sengkarang pada tahun 2031 untuk parameter Loss Model (SCS Curve Number). 
Tabel 4.4 Nilai CN, Impervious dan Initial Abstraction DAS Sengkarang Tahun 2031

\begin{tabular}{|c|c|c|c|}
\hline Sub DAS & CN & Impervious & Inizial Abstraction \\
\hline Sub DAS 0 & 85,48 & 15,48 & 8,63 \\
\hline Sub DAS 1 & 83,37 & 29,93 & 10,13 \\
\hline Sub DAS 2 & 73,81 & 10,24 & 18,03 \\
\hline Sub DAS 3 & 75,64 & 13,81 & 16,36 \\
\hline Sub DAS 4 & 91,63 & 64,73 & 4,64 \\
\hline Sub DAS 5 & 72,73 & 7,38 & 19,05 \\
\hline Sub DAS 6 & 80,77 & 33,44 & 12,10 \\
\hline Sub DAS 7 & 73,67 & 13,27 & 18,15 \\
\hline Sub DAS 8 & 74,52 & 9,54 & 17,37 \\
\hline Sub DAS 9 & 72,03 & 7,55 & 19,72 \\
\hline Sub DAS 10 & 72,01 & 6,84 & 19,74 \\
\hline Sub DAS 11 & 73,85 & 9,01 & 17,99 \\
\hline Sub DAS 12 & 73,18 & 10,42 & 18,61 \\
\hline Sub DAS 13 & 71,12 & 7,44 & 20,63 \\
\hline Sub DAS 14 & 72,17 & 6,17 & 19,59 \\
\hline Sub DAS 15 & 82,27 & 34,00 & 10,95 \\
\hline Sub DAS 16 & 80,57 & 15,00 & 12,25 \\
\hline Sub DAS 17 & 75,32 & 15,90 & 16,65 \\
\hline Sub DAS 18 & 75,74 & 7,20 & 16,27 \\
\hline Sub DAS 19 & 73,19 & 9,40 & 18,61 \\
\hline Sub DAS 20 & 76,78 & 11,83 & 15,37 \\
\hline Sub DAS 21 & 87,06 & 52,30 & 7,55 \\
\hline Sub DAS 22 & 82,72 & 20,91 & 10,61 \\
\hline Sub DAS 23 & 83,23 & 35,30 & 10,24 \\
\hline Sub DAS 24 & 81,08 & 25,86 & 11,86 \\
\hline Sub DAS 25 & 74,17 & 9,76 & 17,69 \\
\hline Sub DAS 26 & 76,22 & 23,67 & 15,85 \\
\hline
\end{tabular}

Tabel 4.5 berikut ini merupakan Lag Time DAS Sengkarang pada tahun 2031 untuk parameter Transfrom Model (SCS Unit Hydrograph Method).

Tabel 4.5 Nilai Lag Time untuk Parameter Transform Model (SCS Unit Hydrograph Method) DAS Sengkarang Tahun 2031

\begin{tabular}{|c|c|}
\hline Sub DAS & Lag Tume (menit) \\
\hline Sub DAS 0 & 34,40 \\
\hline Sub DAS 1 & 11,67 \\
\hline Sub DAS 2 & 2,11 \\
\hline Sub DAS 3 & 1,41 \\
\hline Sub DAS 4 & 0,62 \\
\hline Sub DAS 5 & 1,41 \\
\hline Sub DAS 6 & 1,06 \\
\hline Sub DAS 7 & 1,29 \\
\hline Sub DAS 8 & 1,30 \\
\hline Sub DAS 9 & 1,53 \\
\hline Sub DAS 10 & 1,70 \\
\hline Sub DAS 11 & 1,40 \\
\hline Sub DAS 12 & 2,86 \\
\hline Sub DAS 13 & 2,83 \\
\hline Sub DAS 14 & 1,56 \\
\hline Sub DAS 15 & 1,20 \\
\hline Sub DAS 16 & 1,17 \\
\hline Sub DAS 17 & 2,09 \\
\hline Sub DAS 18 & 2,36 \\
\hline Sub DAS 19 & 2,98 \\
\hline Sub DAS 20 & 2,16 \\
\hline Sub DAS 21 & 2,62 \\
\hline Sub DAS 22 & 7,08 \\
\hline Sub DAS 23 & 1,69 \\
\hline Sub DAS 24 & 4,81 \\
\hline Sub DAS 25 & 2,73 \\
\hline Sub DAS 26 & 3,35 \\
\hline
\end{tabular}

\subsection{Hasil Simulasi}

Hasil simulasi merupakan titik pada Pos Bendung Ps. Kletak. Berikut ini merupakan grafik hasil simulasi debit puncak (Peak Dischange) yang ditunjukkan pada Gambar 4.3 dan 4.4 yang merupakan hidrograf aliran DAS Sengkarang pada tahun 2011 dan tahun 2031 untuk periode ulang 2 tahun dan periode ulang 50 tahun. 


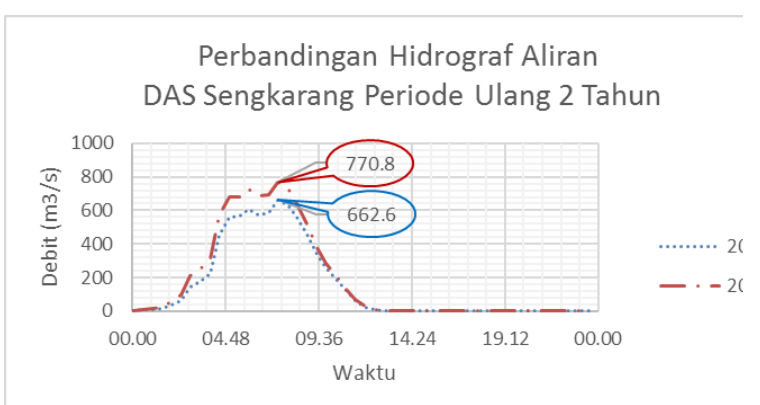

Gambar 4.3. Hidrograf Aliran DAS

Sengkarang Periode Ulang 2 tahun

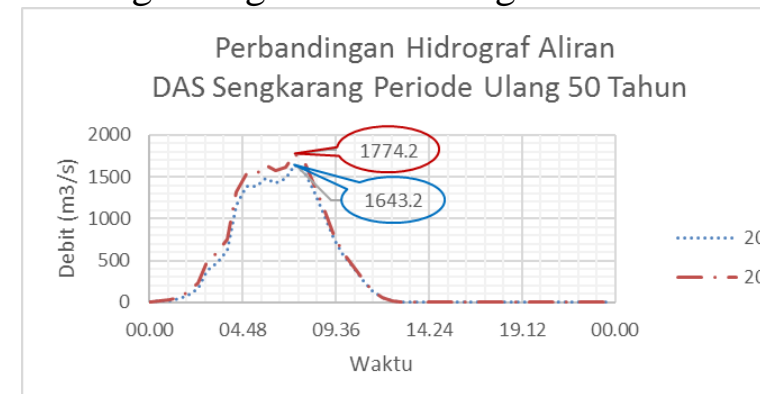

Gambar 4.4. Hidrograf Aliran DAS

Sengkarang Periode Ulang 50 tahun

\section{PENUTUP}

\subsection{Kesimpulan}

Berikut ini merupakan kesimpulan yang dapat diambil dari hasil analisis yang telah dilakukan:

1. Karakateristik daerah aliran sungai pada DAS Sengkarang dengan luas wilayah 270,72 $\mathrm{km}^{2}$ memiliki bentuk DAS memanjang dengan pola aliran dendritik. Jenis tanah yang terdapat pada DAS ini berupa aluvial dan latosol. Perubahan penggunaan lahan antara tahun 2011 sampai 2031 secara signifikan pada wilayah kebun, pemukiman, dan belukar. Wilayah kebun mengalami peningkatan sebesar 13,11\%, sedangkan wilayah pemukiman mengalami peningkatan sebesar $2,92 \%$ dan wilayah belukar mengalami penurunan sebesar $15,04 \%$. Hal ini dikarenakan pertumbuhan penduduk yang meningkat sehingga semakin meningkat pula pembangunan perumahan serta lahan perkebunan.
2. Hasil hidrograf aliran DAS Sengkarang menunjukkan bahwa terjadi peningkatan debit banjir pada tahun 2031 dibandingkan tahun 2011. Peningkatan maksimal terjadi pada periode ulang 2 tahun sebesar $16,33 \%$. Peningkatan debit banjir ini disebabkan oleh perubahan tata guna lahan tahun 2031 dimana penggunaan lahan untuk peresapan berkurang.

3. Hasil debit banjir simulasi DAS Sengkarang pada tahun 2011 untuk periode ulang 2 tahun sebesar 662,6 $\mathrm{m}^{3} / \mathrm{s}$ sedangkan pada tahun 2031 sebesar 770,8 $\mathrm{m}^{3} / \mathrm{s} \quad$ sehingga mengalami kenaikan sebesar $16,33 \%$ dan periode ulang 50 tahun debit banjir pada tahun 2011 dan tahun 2031 sebesar $1643,2 \mathrm{~m}^{3} / \mathrm{s}$ dan $1774,2 \mathrm{~m}^{3} / \mathrm{s}$ mengalami kenaikan $7,97 \%$.

\subsection{Saran}

Berdasarkan hasil analisa debit banjir DAS Beringin perubahan penggunaan wilayah terbesar terdapat pada daerah kebun, pemukiman, sawah dan tegalan. Dari kesimpulan tersebut, penulis memberikan beberapa saran untuk penanggulangan banjir. Beberapa saran tersebut yaitu:

1. Perlu dilakukan reboisasi dengan menanam pohon di sekitar Daerah Aliran Sungai Sengkarang dan melakukan sistem tebang pilih dengan menebang pohon yang sudah tua atau sudah siap digunakan kemudian melakukan penanaman pohon kembali.

2. Melakukan penanaman pohon atau tanaman hijau pada daerah pemukiman agar pemukiman memiliki area peresapan air sehingga mengurangi resiko banjir.

3. Masyarakat sekitar Daerah Aliran Sungai Sengkarang dihimbau untuk tidak membuang sampah di sekitar 
bantaran Sungai Sengkarang agar tidak menimbulkan banjir.

\section{DAFTAR PUSTAKA}

Asdak, C. 2002. Hidrologi dan Pengelolaan daerah Aliran Sungai. Gajah Mada University Press. Yogyakarta.

BAPPEDA Provinsi Jawa Tengah. 2011. Rencana Tata Ruang dan Wilayah (RTRW) Kabupaten Pekalongan Tahun 2011 dan 2031

Brooks KN, Folliot PF, Gregesen HM, and Thames JL. 1987. Hydrology and The Management of Watershed. USA.

Davis, CA. 2000. HEC-HMS Technical Reference Manual. USACE-HEC. diakses pada 17/03/2018

Hermawan, Y, et al 1989. Hidrologi untuk Insinyur (Edisi Ketiga). Jakarta: Penerbit Erlangga.

Linsley, R.K dan Franzini,J.B. Terjemahan Djoko Sasongko. 1991. Teknik Sumber Daya Air Jilid 1. Erlangga. Jakarta

Peraturan Pemerintah Nomor 16 Tahun 2004 tentang Penatagunaan Tanah

Rahayu, Harkunti P. 2009. Banjir dan Upaya penanggulangannya. Bandung: Promise Indonesia

Sindonews. 2018. Tanggul Muara Sungai Sengkarang Jebol, Banjir Pekalongan Sulit Diatasi, diakses 05/02/2018

Soewarno. 1995. Hidrologi Aplikasi Metode Statistik Untuk Analisa Jilid 1. Bandung: Nova.

Soemarto, C. D. 1999. Hidrologi Teknik. Jakarta: Penerbit Erlangga.

Suhartanto, Ery. 2008. Panduan HEC$H M S$. Malang : CV Citra. 